\title{
Produção de matéria seca, composição da massa de forragem e relação lâmina foliar/caule + bainha de aveia-preta e triticale nos sistemas de corte e de pastejo
}

\author{
Fernando Silveira Ferolla², Hernán Maldonado Vásquez ${ }^{3}$, José Fernando Coelho da Silva ${ }^{3}$, \\ Alexandre Pio Viana ${ }^{4}$, Felipe Nogueira Domingues ${ }^{5}$, Rogério da Silva Aguiar 6
}

1 Parte do trabalho de tese de Mestrado do primeiro autor.

${ }^{2}$ Laboratório de Zootecnia e Nutrição Animal (LZNA), Centro de Ciências e Tecnologias Agropecuárias (CCTA), Universidade Estadual do Norte Fluminense (UENF), Av. Alberto Lamego, 2000, Campos dos Goytacazes, RJ CEP: 28015-620.

${ }^{3}$ LZNA/CCTA/UENF e bolsista de produtividade em Pesquisa (CNPq).

${ }^{4}$ Laboratório de Melhoramento Genético Vegetal (LMGV), CCTA/UENF.

${ }^{5}$ Laboratório de Zootecnia e Nutrição Animal (LZNA), CCTA/UENF.

${ }^{6}$ Técnico de apoio, Laboratório de Zootecnia e Nutrição Animal (LZNA), CCTA/UENF.

RESUMO - Com o objetivo de avaliar a viabilidade técnica de produção forrageira de culturas de inverno sob os sistemas de corte e pastejo nas condições do norte do estado do Rio de Janeiro, foram semeadas em abril (21/4/2004), maio (20/5/2004) e junho de 2004 (21/06/2004) as forrageiras aveia-preta (Avena strigosa Schreb) cv. EMBRAPA 29 e triticale (X triticosecale Wittmack) cv. IAC 3. A produção de MS foi maior no sistema corte e na época maio. No sistema de corte, a aveia-preta produziu em média 2.317,48 kg MS/ha e o triticale, 2.128,30 kg MS/ha, ao passo que, no sistema pastejo, produziram 1.169,42 e 678,31 kg MS/ha, respectivamente. As condições climáticas no momento do 1o corte/pastejo anteciparam o ciclo fenológico, o que comprometeu a expressão do potencial produtivo destes cultivares reduzindo o período da germinação ao florescimento e aumentando o percentual de caule + bainha e inflorescência na massa de forragem. A massa de forragem foi composta em média por 34\% de lâmina foliar, 31,08\% de caule + bainha, 24,56\% de inflorescência e 10,35\% de material morto. A proporção de caule + bainha foi maior na aveia-preta. A relação lâmina foliar/caule + bainha diferiu significativamente entre espécies e épocas de plantio e não foi influenciada pelo sistema. Na época junho, a aveia-preta apresentou maior relação lâmina foliar/ caule + bainha, portanto, a menor produção de MS, em virtude do estádio em que as plantas se encontravam no momento das primeiras avaliações. O triticale, apesar da maior participação de inflorescência, apresentou maior relação lâmina foliar/caule + bainha e não diferiu significativamente entre os tratamentos. A melhor época para plantio do triticale na região norte do Rio de Janeiro é abril e para plantio de aveia-preta é maio/junho, ambos no sistema de corte.

Palavras-chave: aveia-preta, forrageira de inverno, produção de MS, relação lâmina foliar/caule + bainha, triticale

\section{Dry matter production, forage mass composition and leaf blade/stem + sheath ratio of black-oat and triticale under cut and grazing}

\footnotetext{
ABSTRACT - The winter forage species Black-oat (Avena strigosa Schreb.) cv. EMBRAPA 29 and triticale (X triticosecale Wittmack.) cv. IAC 3, were studied on three planting dates, April (4/21/2004), May (5/20/2004), and June (6/21/2004) in order to evaluate the technical viability of forage produced under harvest and grazing, in the Northern Region of Rio de Janeiro State. DM production was greater for the harvest system when planted in May, where Black-oat produced 2,317.48 $\mathrm{kg} \mathrm{DM} / \mathrm{ha}$ and triticale 2,128.30 kg DM/ha, compared to 1,169.42 e $678.31 \mathrm{~kg} \mathrm{MS} / \mathrm{ha}$ for black oat and triticale under grazing, respectively. Climatic conditions by the onset of the first cut/grazing anticipated the physiological cycle of these crops, reducing the production potential by decreasing the germination-blooming period and increasing the percentage of stem and inflorescences in the forage mass. The forage mass was composed by $34 \%$ of leaf blade, $31.08 \%$ stem, $24.56 \%$ of inflorescences, and $10.35 \%$ of dead material. Black oat showed greater stem + sheath proportion. Black oat species planted in June showed higher leaf blade/stem + sheath ratio, due to the initial stage when plants were submitted to the first evaluation. Despite the higher contribution of inflorescences, triticale species presented a higher leaf blade/stem + sheath ratio, however with no significant difference among treatments. The best planting time for triticale is April, while that for the Black-oat, May/June, both under the cutting system.
}

Key Words: black oat, DM production, leaf blade/stem + sheath ratio, triticale, winter forage 


\section{Introdução}

A pecuária bovina no norte do estado do Rio de Janeiro, assim como em praticamente todo o Brasil, é explorada em sistemas de pastagem. Por isso, é importante buscar o aprimoramento dos índices nutricionais dos animais nesses sistemas. A principal meta é fornecer volumoso de qualidade ao longo do ano e, considerando o avanço da maturidade e a sazonalidade da produção de forragem, torna-se constante a procura por alternativas de suplementação de inverno. A exploração de forrageiras de inverno tem sido utilizada como alternativa, uma vez que estas espécies constituem forragem de boa qualidade e com significativa produção de matéria seca (Alvim, 1989). Faria \& Corsi (1995) indicaram estas culturas nas condições do Brasil Central, com plantios recomendados em março-abril, objetivando o crescimento das plantas nos meses de temperaturas mais baixas. Esses autores relataram produções de MS de 3 a 5 t/hectare, com cortes a cada 30-35 dias, o que representa produções inferiores às de plantas de clima tropical, porém de alto valor nutritivo.

A aveia-preta (Avena strigosa Schreb) é uma forrageira originária da Europa, de crescimento cespitoso, com colmos eretos e glabros e inflorescência em panícula. Apresenta crescimento inicial rápido, com alta produção no primeiro corte ou pastejo. O plantio deve ser realizado a partir de maio, a lanço ou em linhas espaçadas em $20 \mathrm{~cm}$.

Campos et al. (1982) avaliaram aveia-preta no sul do Espírito Santo e obtiveram produção média de $3.133 \mathrm{~kg}$ MS/ha no primeiro ano de avaliação, em plantios iniciados em abril ou maio, espaçados em 15 dias. A maior produção de MS foi obtida quando o plantio foi realizado na primeira quinzena de maio, avaliado aos 75 dias de idade. No segundo ano, o plantio realizado em $15 / 5$, com o primeiro corte aos 60 dias de crescimento, proporcionou maior produção.

Primavesi et al. (2001) estudaram o momento ideal para o primeiro corte de três cultivares de Avena spp. e utilizaram como critérios para o primeiro corte: 60 dias pós-emergência, início do emborrachamento e $10 \%$ das plantas alongando o caule, com cortes a intervalos de 28 e 56 dias. Entretanto, a partir do segundo ano, o critério de corte da rebrota foi alterado por promover a redução do ciclo das plantas após o primeiro corte. Os cortes passaram a ser realizados, então, a intervalos de 28, 35, 42 e 56 dias.

Teixeira et. al. (2002) avaliaram os cultivares de aveiapreta (Crioula e Ibiporã) e um cultivar de aveia-amarela (São Carlos) adubados com quatro níveis de nitrogênio (0, 90, 180, e $270 \mathrm{~kg} \mathrm{~N} / \mathrm{ha}$ ), nas dependências da UFRRJ, com plantio em 10/7/1999 e um único corte em 2/10/1999. A produção de MS não diferiu significativamente entre os cultivares (1.063; 799 e $663 \mathrm{~kg}$ MS/ha para os cultivares Crioula, São Carlos e Ibiporã, respectivamente), no entanto, foi influenciada pelas doses de N. Cecato et al. (2001) estudaram a produção e a qualidade de cultivares e linhagens de aveia (Avena spp.) no período de abril a setembro e observaram produções de MS de 6.791 a 11.036 kg/ha, de modo que o cultivar FAPA 2 revelou maior produção de lâmina foliar e o SI00061, a menor.

O triticale ( $X$ triticosecale Wittmack) é uma planta anual obtida a partir do cruzamento do trigo com o centeio, portanto, morfologicamente intermediária entre estas duas culturas. Apresenta grãos e espigas semelhantes aos do trigo e a rusticidade do centeio. É utilizado em diversos países para a produção de grãos e/ou de forragem e seu plantio é feito partir de março, preferencialmente em linhas espaçadas a $20 \mathrm{~cm}$, com 80 a $90 \mathrm{~kg}$ de sementes por hectare.

Em estudo com triticale em dois locais na Espanha e sob dois estádios ao corte, na fase de elongação do caule e no perfilhamento, Royo et al. (1994) observaram que o rendimento de grãos foi reduzido em $16 \%$ quando a forragem foi colhida no perfilhamento e em $33 \%$ quando colhida na fase de elongação. Reis et al. (2002) estudaram espécies de inverno sob dois cortes e obtiveram produção de MS de 6,89 t/ha. Esses autores observaram que o cultivar CB-02 superou em produção as demais espécies estudadas, contudo, foi semelhante quando consorciado com aveia-preta.

Este trabalho foi realizado com o objetivo de avaliar a produção de MS, a composição da massa de forragem e a relação lâmina foliar/caule+bainha de aveia-preta e triticale sob os sistemas corte e pastejo semeadas em três épocas diferentes visando melhor aproveitamento no período da seca.

\section{Material e Métodos}

O experimento foi realizado em Campos dos Goytacazes, nas dependências do setor de forragicultura do campo experimental da UENF (Universidade Estadual do Norte Fluminense). O município localiza-se a $21^{\circ} 44^{\prime} 47^{\prime \prime}$ de latitude Sul e $41^{\circ} 18 ' 24$ " de longitude Oeste, em altitude de $12 \mathrm{~m}$. O clima, segundo classificação de Köppen, é descrito como Aw, quente e úmido, com verão chuvoso e temperatura média de $24^{\circ} \mathrm{C}$ e precipitação pluviométrica de $1.023 \mathrm{~mm}$.

O solo é classificado como Latossolo Amarelo Distrófico, classe textural franco-argilo-arenosa, com 54\% de areia, $7 \%$ de silte e $39 \%$ de argila, e apresentou as seguintes características: $\mathrm{pH}$ em água $=5,2 ; \mathrm{P}=5 \mathrm{mg} / \mathrm{dm}^{3}$; 
$\mathrm{S}-\mathrm{SO}^{4}=3 \mathrm{mg} / \mathrm{dm}^{3} ; \mathrm{Ca}=17,5 \mathrm{mmol}_{\mathrm{e}} / \mathrm{dm}^{3} ; \mathrm{Mg}=8,3 \mathrm{mmol}_{\mathrm{c}} / \mathrm{dm}^{3}$; $\mathrm{K}=1,8 \mathrm{mmol}_{\mathrm{c}} / \mathrm{dm}^{3} ; \mathrm{Al}=1,0 \mathrm{mmol}_{\mathrm{c}} / \mathrm{dm}^{3} ; \mathrm{H}+\mathrm{Al}=$ $27,7 \mathrm{mmol} / \mathrm{dm}^{3} ; \mathrm{MO}=26,0 \mathrm{~g} / \mathrm{dm}^{3} ; \mathrm{CTC}=55,8 \mathrm{mmol} / \mathrm{dm}^{3}$; $\mathrm{V} \%=50 \% ;$ Sat $\mathrm{Al}=3 \% ; \mathrm{Fé}=39,8 \mathrm{mg} / \mathrm{dm}^{3} ; \mathrm{Cu}=0,4 \mathrm{mg} / \mathrm{dm}^{3}$; $\mathrm{Zn}=2,1 \mathrm{mg} / \mathrm{dm}^{3} ; \mathrm{Mn}=6,2 \mathrm{mg} / \mathrm{dm}^{3}$ e B $=0,24 \mathrm{mg} / \mathrm{dm}^{3}$. Aplicou-se calcário na quantidade de $1 \mathrm{t} / \mathrm{ha}$.

O delineamento experimental foi o de blocos ao acaso, em esquema fatorial $2 \times 2 \times 3$, com três repetições, considerando fatores a espécie, o sistema e a época de plantio. Os cultivares de aveia-preta (Avena strigosa Schreb.) cv. EMBRAPA 29 (Garoa) e triticale (X triticosecale Wittmack) cv. IAC 3 foram semeados a uma densidade de $100 \mathrm{~kg}$ de sementes/ha, em três épocas (abril, maio e junho), e colhidos em dois sistemas (corte e pastejo).

Como adubação de plantio, aplicou-se superfosfato simples (500 kg/ha), junto com as sementes. Aos 20 dias após o plantio, aplicou-se adubação de cobertura, com $20 \mathrm{~kg} \mathrm{~N} / \mathrm{ha} \mathrm{na} \mathrm{forma} \mathrm{de} \mathrm{uréia} \mathrm{e} 10 \mathrm{~kg}$ de $\mathrm{K}_{2} \mathrm{O} / \mathrm{ha}$. Após cada corte/pastejo, foram também aplicadas em cobertura as doses de $90 \mathrm{~kg} \mathrm{~N} / \mathrm{ha}$ e $30 \mathrm{~kg} \mathrm{~K} \mathrm{~K}_{2} \mathrm{O} / \mathrm{ha}$. As parcelas foram concomitantemente irrigadas por uma hora em turnos espaçados a intervalos de um dia, até próximo ao ponto de escorrimento.

As parcelas de corte mediam $25 \mathrm{~m}^{2}(5 \times 5 \mathrm{~m})$ e, no momento do corte, foram eliminadas faixas de $1 \mathrm{~m}$ nas bordaduras. Após o corte, realizado a $10 \mathrm{~cm}$ do solo, foram retiradas amostras representativas para determinação da composição da massa, da relação lâmina foliar/caule+bainha e do teor de MS.

As parcelas de pastejo mediam $100 \mathrm{~m}^{2}(10 \times 10 \mathrm{~m})$. Antes de cada pastejo, três amostras foram coletadas por meio de uma unidade amostral de $1 \mathrm{~m}^{2}$ para determinação do peso fresco e alíquotas representativas foram retiradas para determinação do teor de MS, da composição da massa de forragem e da relação lâmina foliar/caule+bainha.

No sistema pastejo, utilizou-se em cada parcela um bovino com peso de aproximadamente $300 \mathrm{~kg}$. Os animais foram mantidos em pastejo durante a noite, das $18 \mathrm{~h}$ às $6 \mathrm{~h}$ do dia seguinte visando preservar resíduo de $20 \mathrm{~cm}$.

$\mathrm{Na}$ época abril, os cortes/pastejos foram realizados aos 60 dias pós-plantio (dpp) e, a partir da época maio, foram realizados aos 45 dias pós-plantio, em decorrência da grande emissão de inflorescências nas primeiras avaliações. A produção total de MS foi calculada como a soma da produção das avaliações obtidas nas três épocas (abril, maio, junho) para cada parcela e a relação folha/caule + bainha, como a soma do peso seco desses componentes da massa de forragem em cada corte/pastejo. A composição da massa forrageira (\%), por sua vez, correspondeu à relação entre o peso seco do componente e o peso seco total da produção de cada tratamento.

Os tratamentos foram definidos como: $\mathrm{AA}^{\mathrm{b}} \mathrm{C}, \mathrm{AMC}$, AJC, $A A^{b} P, A M P, A J P$ e $T A^{b} C, T M C, T J C, T A^{b} P, T M P$, TJP, em que $A=$ aveia-preta; $T=$ triticale; $A^{b}=$ época de plantio abril; $\mathrm{M}=$ época de plantio em maio; $\mathrm{J}=$ época de plantio junho; $\mathrm{C}$ = sistema de corte; e $\mathrm{P}$ = sistema de pastejo.

O modelo estatístico foi expresso como:

$$
\begin{aligned}
\mathrm{Y}= & \mu+\mathrm{Sis}_{\mathrm{p}}+\mathrm{Sp}_{\mathrm{i}}+\mathrm{Epc}_{\mathrm{j}}+\mathrm{Sis}_{\mathrm{p}} \times \mathrm{Sp}_{\mathrm{i}}+\mathrm{Sis}_{\mathrm{p}} \times \mathrm{Epc}_{\mathrm{i}}+ \\
& \mathrm{Sp}_{\mathrm{i}} \times \mathrm{Epc}_{\mathrm{j}}+\mathrm{Sis}_{\mathrm{p}} \times \mathrm{Sp}_{\mathrm{i}} \times \mathrm{Epc}_{\mathrm{j}}+\mathrm{B}_{\mathrm{k}}+\mathrm{e}_{\mathrm{pijk}},
\end{aligned}
$$

em que $\mu=$ média geral; Sis $_{p}=$ sistema de produção (corte ou pastejo); $\mathrm{Sp}_{\mathrm{i}}=$ espécie cultivada; $\mathrm{Epc}_{\mathrm{j}}=$ uma das três épocas de plantio; $\mathrm{B}_{\mathrm{k}}=$ efeito do bloco; $\mathrm{Sis}_{\mathrm{p}} \times \mathrm{SP}_{\mathrm{i}}=$ interação sistema de uso $\times$ espécie; $\operatorname{Sis}_{\mathrm{p}} \times \mathrm{Epc}_{\mathrm{j}}=$ interação sistema de uso $\times$ época de plantio; $\mathrm{Sp}_{\mathrm{i}} \times \mathrm{Epc}_{\mathrm{j}}=$ interação espécie forrageira $\times$ época de plantio; $\mathrm{Sis}_{\mathrm{p}} \times \mathrm{Sp}_{\mathrm{i}} \times \mathrm{Epc}_{\mathrm{j}}=$ interação tripla dos fatores; e $\mathrm{e}_{\mathrm{ijk}}=$ erro experimental. Os resultados foram submetidos ao teste Tukey, a 5\% de significância, pelo programa estatístico GENES, e a análise de variância foi realizada pelo programa SAS, procedimento GLM(SAS, 1996).

\section{Resultados e Discussão}

Houve efeito significativo $(\mathrm{P}<0,05)$ de um ou de mais fatores (espécie, sistema de corte, época de plantio) e de suas interações sobre a produção de MS, as porcentagens de lâmina foliar (\%lf) e inflorescência (\%Inf) na MS total (\% lf, \% Inf). A produção de MS foi maior nas duas forrageiras semeadas em maio e o sistema corte foi superior ao pastejo $(\mathrm{P}<0,05)$.

A produção de MS (Tabela 1) da aveia-preta, tanto no sistema corte como no pastejo (3.426,26 e $2.710,47 \mathrm{~kg} / \mathrm{ha}$, respectivamente), foi maior que do triticale (1.419,76 e $1.165,60 \mathrm{~kg} / \mathrm{ha}$, respectivamente). As espécies forrageiras estudadas atingiram a fase reprodutiva precocemente em relação ao descrito na literatura (EMBRAPA CNPT, 2000). As primeiras observações da época abril revelaram completa emissão da inflorescência em ambas as espécies aos 60 dias pós-plantio, principalmente no triticale, em virtude do grande encurtamento do ciclo vegetativo. Segundo a lei de VAN'T $\mathrm{HOFF}$, a cada $10^{\circ} \mathrm{C}$ de aumento na temperatura, a produção de MS dobra (Assis, 2004). A esta lei foi atribuído o conceito da relação entre temperatura e taxa de desenvolvimento de uma planta, pois determinadas fases de desenvolvimento são antecipadas quando há aumentos progressivos de temperatura, o que está de acordo com informações de Felício \& Camargo et al. (2001). As unidades térmicas de desenvolvimento vegetal são baseadas na temperatura 
acumulada em grau-dia, índice obtido pela diferença entre a temperatura média diária e a temperatura-base da planta, abaixo da qual os processos metabólicos estabilizam ou paralizam. Estas unidades são utilizadas na determinação das exigências térmicas para uma cultura atingir determinado estádio fisiológico, o que permite prever a adaptação às diversas regiões e as melhores épocas de semeadura.

Esse conhecimento permite favorecer a adaptação de espécies, como plantas de inverno em clima tropical, e obter condições para estabelecê-las com produções significativas. Os materiais genéticos, por sua vez, respondem de forma diferente ao acúmulo de graus-dia e podem ser classificados como de ciclo precoce, médio ou tardio em relação à emissão das inflorescências.

Pedro Jr. et al. (2004), estudando cultivares de triticale, encontraram para a cv. IAC 3 período médio da emergência ao florescimento de 56,2 dias, soma de graus-dia da emergência à maturação de $1.263^{\circ} \mathrm{C}$ e temperatura de base $8^{\circ} \mathrm{C} \mathrm{e}$ classificaram esse cultivar como precoce nas condições de Capão Bonito, estado de São Paulo. Esses trabalhos destacam a necessidade de se conhecer a constante térmica na escolha de um material genético para utilização em diferentes regiões geográficas a fim de explorar o máximo da fase desejada da cultura.

A aveia-preta no sistema corte e na época abril, ao sofrer o primeiro corte, apresentava completa emissão da inflorescência e não produziu rebrote. Portanto, sua produção resultou de um único corte em comparação à época maio, que possibilitou maior produção de MS, três cortes, e à época junho, dois cortes (Tabela 1).

No sistema pastejo, este comportamento não se confirmou, provavelmente em virtude da preservação dos meristemas (resíduo de $20 \mathrm{~cm}$ ), em razão do pastejo das inflorescências no início do desenvolvimento. Nesse sistema, a quantidade de MS produzida foi maior na época abril, que superou maio, seguida de junho, com três pastejos no plantio da época maio, seguida de abril e junho, respectivamente, com dois pastejos. A produção de MS/ha nos dois cultivares estudados (Tabela 1) foi expressiva quando comparada à de outros trabalhos. Pedro Jr. et al. (2003), avaliando três cultivares de aveia branca e um de aveiapreta, semeados em maio e aos 63 dias pós-pastejo mais duas rebrotas, obtiveram 1,21; 1,73 e 1,84 t de MS/ha. Teixeira et al. (2002) no Rio de Janeiro, em um único corte, obtiveram 0,66; 0,79 e 1,06 t de MS/ha. Gomes \& Stumpf (2001) testaram diferentes níveis de $\mathrm{N}$ e obtiveram 5,9 t de MS/ha de aveia-preta no nível de $260 \mathrm{~kg}$ de N/ha (EMBRAPA 29). Sá \& Oliveira (1995), estudando genótipos de ciclos diferentes, obtiveram produções que variaram de 1,98 a 6,86

Tabela 1 - Produção de MS (kg MS/ha) de aveia-preta e triticale e relação lâmina foliar/caule + bainha obtidas com diferentes época de plantio em sistemas de corte e pastejo

Table 1 - DM production ( $\mathrm{kg} \mathrm{DM} / \mathrm{ha}$ ) of black oat and triticale and leaf blade/stem + sheath ratio for each planting season and utilization system

\begin{tabular}{lccc}
\hline & \multicolumn{3}{c}{$\begin{array}{c}\text { Aveia-preta } \\
\text { Black-oat }\end{array}$} \\
\cline { 2 - 4 } $\begin{array}{l}\text { Sistema } \\
\text { System }\end{array}$ & $\begin{array}{c}\text { Abril } \\
\text { April }\end{array}$ & $\begin{array}{c}\text { Maio } \\
\text { May }\end{array}$ & $\begin{array}{c}\text { Junho } \\
\text { June }\end{array}$ \\
\hline $\begin{array}{l}\text { Corte } \\
\text { Harvest } \\
\text { Pastejo }\end{array}$ & $839,91 \mathrm{Bc}$ & $3.426,26 \mathrm{Aa}$ & $2.686,28 \mathrm{Ab}$ \\
$\begin{array}{l}\text { Grazing } \\
\text { Sistema }\end{array}$ & $1.419,76 \mathrm{Aa}$ & $1.384,17 \mathrm{Bb}$ & $704,32 \mathrm{Bc}$ \\
$\begin{array}{l}\text { System } \\
\text { Corte }\end{array}$ & & & \\
Harvest & & & \\
Pastejo & & & \\
Grazing & $1.803,84 \mathrm{Ac}$ & $2.710,47 \mathrm{Aa}$ & $1.870,58 \mathrm{Ab}$ \\
\hline
\end{tabular}

Espécie

Specie

Aveia-preta

Black-oat

Triticale

Médias na coluna/linha, seguidas pela mesma letra maiúscula/minúscula não diferem $(P>0,05)$ pelo teste Tukey.

Means in the column/row, followed by the same capital/small letter do not differ $(P>0.05)$ by Tukey test.

de acordo com a idade de corte e Cecato et al. (2001), em experimento com diferentes materiais genéticos no Paraná, obtiveram produções de 6,7 a 11,03 t de MS/ha.

As produções de matéria seca do triticale diferiram estatisticamente $(\mathrm{P}<0,05)$ entre os sistemas e as épocas de plantio. Houve interações de sistema e época de plantio e entre os três fatores estudados. O plantio na época maio proporcionou maior produção de MS, em decorrência do maior número de avaliações. O plantio na época abril com corte mais tardio (60 dias pós-pastejo) provocou completa emissão de inflorescências e, portanto, reduzida participação da lâmina foliar na massa total do triticale. Esse resultado pode estar relacionado à classificação do ciclo deste cultivar citada anteriormente (Felício et al., 2001; Saran Jr. et al., 2004) e ao intenso ataque de saúvas (Atta spp.), que prejudicou a formação do estande nas parcelas de pastejo na época junho.

A aveia-preta semeada na época junho apresentou maior relação lâmina foliar/caule+bainha em comparação à época maio e à época abril, uma vez que a menor soma térmica alcançada no momento do primeiro corte/pastejo na época junho permitiu a realização ainda em estádio fisioló- 
gico inicial, possivelmente considerado muito precoce para o início da utilização do material, que pode também ter comprometido a produção de matéria seca por hectare (Tabela 1$)$. $\mathrm{O}$ triticale não diferiu $(\mathrm{P}>0,05)$ quanto à relação lâmina foliar/caule+bainha entre os sistemas e as épocas de plantio, apesar da grande participação de inflorescência na massa produzida (Tabela 2) e da ausência de diferença significativa entre os tratamentos pelo teste Tukey $(\mathrm{P}>0,05)$ quanto à produção de lâmina foliar.

Os dados relativos à relação lâmina foliar/caule + bainha confirmam a observação de que o desenvolvimento fisiológico das plantas reduziu a participação de lâminas foliares na composição da massa total, ressaltando a diferença entre os cultivares, e foi influenciado também

Tabela 2 - Porcentagem de lâmina foliar e inflorescência na massa forrageira de aveia-preta e triticale semeados em diferentes épocas de plantio nos sistemas de corte e de pastejo

Table 2 - Percentage of leaf blade and inflorescences of black oat and triticale forage mass according to species, harvesting system and planting seasons

\begin{tabular}{|c|c|c|c|c|}
\hline \multirow[b]{3}{*}{$\begin{array}{l}\text { Espécie } \\
\text { Specie }\end{array}$} & \multicolumn{4}{|c|}{$\begin{array}{l}\text { \% lâmina foliar } \\
\text { \% leaf blade }\end{array}$} \\
\hline & \multicolumn{4}{|c|}{$\begin{array}{l}\text { Época de plantio } \\
\text { Planting season }\end{array}$} \\
\hline & $\begin{array}{l}\text { Abril } \\
\text { April }\end{array}$ & $\begin{array}{l}\text { Maio } \\
\text { May }\end{array}$ & $\begin{array}{l}\text { Junho } \\
\text { June }\end{array}$ & $\begin{array}{l}\text { Média } \\
\text { Mean }\end{array}$ \\
\hline $\begin{array}{l}\text { Aveia-preta } \\
\text { Black oat }\end{array}$ & $21,68 \mathrm{c}$ & $27,44 b$ & $45,41 \mathrm{a}$ & $31,51 \mathrm{~A}$ \\
\hline & $\begin{array}{l}41,14 \mathrm{a} \\
31,41 \mathrm{~B}\end{array}$ & $\begin{array}{l}31,79 b \\
29,61 B\end{array}$ & $\begin{array}{l}25,69 \mathrm{c} \\
35,55 \mathrm{~B}\end{array}$ & $33,04 \mathrm{~A}$ \\
\hline & \multicolumn{4}{|c|}{$\begin{array}{l}\text { \% inflorescência } \\
\text { \% inflorescence }\end{array}$} \\
\hline & \multicolumn{4}{|c|}{$\begin{array}{l}\text { Corte } \\
\text { Harvest }\end{array}$} \\
\hline $\begin{array}{l}\text { Espécie } \\
\text { Specie }\end{array}$ & $\begin{array}{l}\text { Abril } \\
\text { April }\end{array}$ & $\begin{array}{l}\text { Maio } \\
\text { May }\end{array}$ & $\begin{array}{l}\text { Junho } \\
\text { June }\end{array}$ & $\begin{array}{l}\text { Média } \\
\text { Mean }\end{array}$ \\
\hline $\begin{array}{l}\text { Aveia-preta } \\
\text { Black oat }\end{array}$ & $13,66 a$ & $14,17 \mathrm{a}$ & $1,91 \mathrm{a}$ & $9,91 \mathrm{~B}$ \\
\hline Triticale & $37,97 \mathrm{a}$ & $29,62 \mathrm{a}$ & $16,06 \mathrm{a}$ & $27,88 \mathrm{~A}$ \\
\hline $\begin{array}{l}\text { Média corte } \\
\text { Mean harvest }\end{array}$ & $25,81 \mathrm{~B}$ & $21,89 \mathrm{~B}$ & $9,94 \mathrm{~B}$ & \\
\hline
\end{tabular}

\begin{tabular}{|c|c|c|c|c|}
\hline \multirow[b]{2}{*}{ Aveia-preta } & \multicolumn{4}{|c|}{$\begin{array}{l}\text { Pastejo } \\
\text { Grazing }\end{array}$} \\
\hline & $38,70 a$ & $18,36 \mathrm{a}$ & $13,50 a$ & $23,52 \mathrm{~B}$ \\
\hline Black oat & & & & \\
\hline Triticale & $18,85 b$ & $31,62 \mathrm{ab}$ & $70,78 a$ & $40,42 \mathrm{~A}$ \\
\hline $\begin{array}{l}\text { Média pastejo } \\
\text { Grazing mean }\end{array}$ & $28,77 \mathrm{~A}$ & $34,17 \mathrm{~A}$ & $42,14 \mathrm{~A}$ & \\
\hline
\end{tabular}

Médias na coluna/linha seguidas pela mesma letra maiúscula/minúscula não diferem pelo teste Tukey $(P>0,05)$.

Means in the column/row, followed by the same capital/small letter do not differ $(P>0.05)$ by Tukey test. pela época de plantio (Tabela 1), não sendo observadas diferenças nesta relação atribuídas ao sistema ( $\mathrm{P}>0,05)$.

A participação da lâmina foliar na massa seca total de forragem diferiu significativamente $(\mathrm{P}<0,05)$ entre cultivares (Tabela 2), mas não diferiu ( $\mathrm{P}>0,05)$ entre as épocas. $\mathrm{O}$ maior número de dias para o primeiro corte na época abril pode ter reduzido a participação da lâmina foliar, que apresentou maior participação nas épocas maio e junho, quando ao primeiro corte apresentavam-se em plena fase vegetativa.

Observou-se tendência de aumento na participação da lâmina foliar e de diminuição da inflorescência (Tabela 2) da época abril para a época junho nas culturas de aveiapreta. O triticale se comportou de forma inversa no sistema pastejo, embora, pelo teste Tukey, as espécies não tenham diferido significativamente quanto à inflorescência.

A massa de caule + bainha diferiu entre as espécies, em virtude do alongamento precoce das hastes, aumentando sua porcentagem na massa, e foi maior na aveia-preta, independentemente do sistema e das épocas de plantio. A quantidade de MS morta nas duas espécies (Tabela 3) foi em média 10,35\% da massa de forragem e diferiu entre os sistemas, como resultado do maior adensamento das plantas no sistema de corte, que conferiu maior competição e sombreamento das folhas basais, induzindo a senescência mais precoce destas folhas.

Os critérios de definição das culturas a serem estabelecidas como pastagem de inverno são a rusticidade e resistência a doenças e pragas, porém, é fundamental o conhecimento

Tabela 3 - Porcentagens de caule + bainha e de MS morta na massa forrageira de aveia-preta e triticale cultivados nos sistemas de corte e de pastejo

Table 3 - $\quad$ Percentages of stem + sheath and dead DM in the forage mass of black oat and triticale for each cutting system

\begin{tabular}{|c|c|c|c|}
\hline \multirow[b]{2}{*}{$\begin{array}{l}\text { Espécie } \\
\text { Specie }\end{array}$} & \multicolumn{3}{|c|}{$\begin{array}{c}\text { \% caule + bainha } \\
\% \text { stem + sheath }\end{array}$} \\
\hline & $\begin{array}{l}\text { Corte } \\
\text { Harvest }\end{array}$ & $\begin{array}{l}\text { Pastejo } \\
\text { Grazing }\end{array}$ & $\begin{array}{l}\text { Média } \\
\text { Mean }\end{array}$ \\
\hline $\begin{array}{l}\text { Aveia-preta } \\
\text { Black oat }\end{array}$ & 41,26 & 36,47 & $38,86 \mathrm{~A}$ \\
\hline \multirow[t]{2}{*}{ Triticale } & 23,84 & 22,40 & $23,12 \mathrm{~B}$ \\
\hline & \multicolumn{3}{|c|}{$\begin{array}{c}\% \text { matéria seca morta } \\
\% \text { dead material }\end{array}$} \\
\hline $\begin{array}{l}\text { Sistema } \\
\text { System }\end{array}$ & $\begin{array}{c}\text { Aveia-preta } \\
\text { Black oat }\end{array}$ & Triticale & $\begin{array}{l}\text { Média } \\
\text { Mean }\end{array}$ \\
\hline $\begin{array}{l}\text { Corte } \\
\text { Harvest }\end{array}$ & 19,10 & 11,72 & $15,41 \mathrm{~A}$ \\
\hline $\begin{array}{l}\text { Pastejo } \\
\text { Grazing }\end{array}$ & 6,39 & 2,25 & $4,32 B$ \\
\hline
\end{tabular}

Médias na coluna seguidas pela mesma letra não diferem $(P>0,05)$ pelo teste Tukey.

Means in the column, followed by the same letter do not differ $(P>0.05)$ by Tukey test. 
do ciclo destas culturas quanto à constante térmica a cada estádio da planta a fim de se obter o maior aproveitamento em cada fase fenológica.

\section{Conclusões}

Na região norte do Rio de Janeiro, a melhor época para plantio de triticale é abril e para plantio de aveia-preta, maio/junho, ambos no sistema de corte.

\section{Literatura Citada}

ALVIM, J.M. Produção e utilização de forrageiras de inverno: aveia e azevém. Coronel Pacheco: EMBRAPA-CNPGL, 1989. 28p. (Documentos, 42).

ASSIS, S.V. [2004]. Disciplina de Agrometeorologia, Unidade 3: Temperatura do ar e plantas cultivadas. Disponível em: <www.ufpel.br/agrometeorologia. Acesso em: 28/4/2005.

CAMPOS, R.M.; GUSS, A.; DESSAUNE, N.F. Épocas de plantio e de colheita de aveia forrageira (Avena strigosa) no sul do estado do Espírito Santo. In: REUNIÂO ANUAL DA SOCIEDADE BRASILEIRA DE ZOOTECNIA 19., 1982, Piracicaba. Anais... Piracicaba: Sociedade Brasileira de Zootecnia, 1982. p.355-356.

CECATO, U.; RÊGO, F.C.A.; GOMES, J.A.N. et al. Produção e composição química em cultivares e linhagens aveia (Avena spp). Acta Scientiarum, v.23, n.4, p.775-780, 2001.

EMBRAPA CNPT. [2000]. VII Reunião Brasileira de Pesquisa de triticale. Disponível em: <www.embrapa.cnpt.org.br> Acesso em: 29/7/2003.

FARIA, V.P.; CORSI, M. Forragens de inverno. PEIXOTO, A.M.; MOURA, J.C.; FARIA, V.P. (Eds.) Volumosos para bovinos. 1.ed. Piracicaba: Fundação de Estudos Agrários Luiz de Queiroz, 1995. p.227-231.

FELICIO, J.C.; CAMARGO, C.E.O.; FERREIRA FILHO, A.W.P. et al. Avaliação de Genótipos de triticale e trigo em ambientes favoráveis e desfavoráveis no Estado de São Paulo. Bragantia, v.60, n.2, p.83-91, 2001.
GOMES, J.F.; STUMPF, JR., W. Intervalos de corte e adubação nitrogenada em Aveia preta EMBRAPA 29 (GAROA). In: REUNIÃO ANUAL DA SOCIEDADE BRASILEIRA DE ZOOTECNIA, 38., 2001, Piracicaba. Anais... Piracicaba: Sociedade Brasileira de Zootecnia, 2001. (CD-ROM).

SARAN JR., A.J.S.; REIS, R.A.; MOREIRA, A.L. et al. Avaliação de cultivares de aveia sob pastejo em Jaboticabal-SP. In; REUNIÃO ANUAL DA SOCIEDADE BRASILEIRA DE ZOOTECNIA, 40., 2003, Santa Maria. Anais... Santa Maria: Sociedade Brasileira de Zootecnia, 2003. (CD-ROM).

PEDRO JR., M.J.; CAMARGO, M.B.P.; MORAES, A.V.C. et al. Temperatura-base, grau-dia e duração do ciclo para cultivares de triticale. Bragantia, v.63, n.3, p.447-453, 2004.

PRIMAVESI, A.C.; PRIMAVESI, O.; CHINELATO, A. et al. Indicadores de determinação de cortes de cultivares de Aveia forrageira. Scientia Agrícola, v.58, n.1, p.79-89, 2001.

REIS, R.A; MOREIRA, A.L.; SEIXAS, P.F. et al. Avaliação de gramíneas anuais de inverno para produção de forragem em Jaboticabal - SP. In: REUNIÃO ANUAL DA SOCIEDADE BRASILEIRA DE ZOOTECNIA, 39., 2002, Recife. Anais... Recife: Sociedade Brasileira de Zootecnia, 2002. (CD-ROM).

ROYO, C.; INSA, J.A.; BOUJENNA, A. et al. Yield and quality of spring triticale for forage and grain as influenced by sowing date and cutting stage. Field Crops Research, v.37, n.3, p.161$168,1994$.

SÁ, J.P.G.; OLIVEIRA, J.C. [1995]. Avaliação de genótipos de aveia preta em Londrina PR. Disponível em: <www.iapar.br> Acesso em: 19/1/2004.

STATISTICAL ANALYSIS SYSTEM - SAS User's guide. Version 6, 4.ed. Cary: 1996. 1686p.

TEIXEIRA, M.C.; ABREU, J.B.R.; MENEZES, J.B.O.X. et al. Efeito de doses de nitrogênio sobre a produção de matéria seca de cultivares de aveia forrageira. In: ZOOTEC, 2002, Rio de Janeiro. Anais... Rio de Janeiro: 2002. (CD-ROM). 